\title{
Transient changes in milk production efficiency and bacterial community composition resulting from near-total exchange of ruminal contents between high- and low-efficiency Holstein cows
}

\author{
Paul J. Weimer, ${ }^{+} \dagger^{1}$ Madison S. Cox, $†$ Tania Vieira de Paula, $\ddagger$ Miao Lin, $\S$ Mary Beth Hall, ${ }^{*}$ and Garret Suen† \\ *US Dairy Forage Research Center, USDA-Agricultural Research Service, Madison, WI 53706 \\ †Department of Bacteriology, University of Wisconsin, Madison \\ ‡Department of Animal Science, Federal University of Mato Grosso, Cuiabá, 78060-900, Brazil \\ §Department of Animal Sciences and Technology, Yangzhou University, Yangzhou, Jiangsu 225009, People's Republic of China
}

\begin{abstract}
The objectives of this study were to determine if milk production efficiency (MPE) is altered by near-total exchange of ruminal contents between high- (HE) and low-MPE (LE) cows and to characterize ruminal bacterial community composition (BCC) before exchange and over time postexchange. Three pairs of ruminally cannulated, third-lactation cows were selected whose MPE (energy-corrected milk per unit of dry matter intake) differed over their first 2 lactations. Approximately $95 \%$ of ruminal contents were exchanged between cows within each pair. Ruminal $\mathrm{pH}$ and volatile fatty acid (VFA) profiles, along with BCC (characterized by sequencing of the variable 4 region of $16 \mathrm{~S}$ rRNA genes), were assessed just before feeding on $\mathrm{d}-8,-7,-5,-4$, $-1,1,2,3,7,10,14,21,28,35,42$, and 56 , relative to the exchange date. High-MPE cows had higher total ruminal VFA concentrations, higher molar percentages of propionate and valerate, and lower molar percentages of acetate and butyrate than did LE cows, and re-established these differences $1 \mathrm{~d}$ after contents exchange. Across all LE cows, MPE increased during $7 \mathrm{~d}$ postexchange but declined thereafter. Two of the $3 \mathrm{HE}$ cows displayed decreases in MPE following introduction of the ruminal contents from the corresponding LE cow, but MPE increased in the third HE cow, which was determined to be an outlier. For all 6 cows, both liquidand solids-associated BCC differed between individuals within a pair before contents exchange. Upon exchange, BCC of both phases in all 3 pairs was more similar to that of the donor inoculum than to preexchange host BCC. For 5 of 6 cows, the solids-associated community returned within $10 \mathrm{~d}$ to more resemble the preexchange
\end{abstract}

Received February 17, 2017.

Accepted May 8, 2017.

${ }^{1}$ Corresponding author: Paul.Weimer@ars.usda.gov community of that host than that of the donor community. Individual variability before the exchange was greater in liquids than in solids, as was the variability in response of bacterial communities to the exchange. Individual cows varied in their response, but generally moved toward re-establishment of their preexchange communities by $10 \mathrm{~d}$ after contents exchange. By contrast, ruminal $\mathrm{pH}$ and VFA profiles returned to preexchange levels within $1 \mathrm{~d}$. Despite the small number of cows studied, the data suggest an apparent role for the ruminal bacterial community as a determinant of MPE. Key words: milk production efficiency, ruminal contents exchange, ruminal microbiome

\section{INTRODUCTION}

Breeding of ruminants for improved production, combined with improvements in feeding and management, have resulted in tremendous gains in livestock productivity and efficiency. Although it is difficult to directly compare efficiency within the dairy industry over long time periods due to changes in feeding and production practices, dairy cows in the United States in 2007 were more efficient and environmentally benign than dairy cows in 1944 (Capper et al., 2009), despite undesirable negative trends in cow longevity and fertility (Dobson et al., 2007). Additional improvements in feed efficiency are considered essential to promote economically and environmentally sustainable dairy production in the future (Connor, 2015), and this might be accomplished in a variety of ways. Experiments with groups of animals fed the same diet indicate substantial differences in production efficiency among animals for both beef cattle (Hernandez-Sanabria et al., 2010, 2012; Carberry et al., 2012) and dairy cows (Connor et al., 2012; Arndt et al., 2015). Although these differences are often ascribed to differences in animal genetics (Pryce et al., 2012; VandeHaar et al., 2016), evidence is accumulating that differences in efficiency are associated with 
WEIMER ET AL.

Table 1. Cows used for ruminal contents exchange experiments

\begin{tabular}{|c|c|c|c|c|c|c|}
\hline Pair & Cow & $\begin{array}{l}\text { Efficiency } \\
\text { status }^{1}\end{array}$ & $\mathrm{DIM}^{2}$ & $\begin{array}{l}\mathrm{BW}^{3} \\
(\mathrm{~kg})\end{array}$ & $\begin{array}{c}\text { Contents } \\
\text { removed }^{4}(\mathrm{~kg})\end{array}$ & $\begin{array}{c}\text { Contents } \\
\text { received }^{5}(\mathrm{~kg})\end{array}$ \\
\hline \multirow[t]{2}{*}{$\overline{1}$} & 4255 & High & 123 & 676 & 84.6 & 82.5 \\
\hline & 4261 & Low & 238 & 833 & 83.4 & 84.4 \\
\hline \multirow[t]{2}{*}{2} & 4273 & High & 279 & 729 & 81.4 & 94.7 \\
\hline & 4282 & Low & 151 & 725 & 95.9 & 80.4 \\
\hline \multirow{2}{*}{3} & 4262 & High & 164 & 679 & 65.8 & 85.4 \\
\hline & 4297 & Low & 79 & 725 & 86.2 & 65.0 \\
\hline
\end{tabular}

${ }^{1}$ Milk production efficiency status (low = less efficient; high = more efficient) based on within-pair comparisons over 2 previous lactations (Jewell et al., 2015; see text).

${ }^{2}$ Days in milk on day of contents exchange.

${ }^{3}$ Mean BW (d $-5,6$, and 7 relative to date of contents exchange).

${ }^{4}$ Fresh weight of liquid and solid ruminal contents removed for transfer to other cow within pair.

${ }^{5}$ Fresh weight of liquid and solid ruminal contents received from other cow within pair.

differences in the composition of the ruminal microbial community, interactions between the microbiome and host genetics, or both (Jami et al., 2014; Jewell et al., 2015; Shabat et al., 2016).

The objective of this study was to determine if differences in milk production efficiency (MPE) are mediated by (rather than merely correlated or associated with) the host bacterial community. We examined changes in ruminal microbial composition and MPE following near-total exchange of ruminal contents between pairs of third-lactation cows that had displayed differences in feed intake at the same within-pair level of milk production over their first 2 lactations. Our hypothesis was that MPE of the cow receiving the ruminal contents would change, at least transiently, to be similar to that of the donor animal, until the original ruminal community composition reverted to more closely resemble that of the cow before contents exchange.

\section{MATERIALS AND METHODS}

\section{Animal Trial}

The study was conducted at the US Dairy Forage Research Center (USDFRC), Prairie du Sac, Wisconsin, under protocol A01427, approved by the College of Agricultural and Life Sciences Animal Care and Use Committee, University of Wisconsin-Madison (UW). Three pairs of ruminally cannulated Holstein cows in their third lactation (cannulated before their first lactation according to a separate protocol, A01307) were used (Table 1). These pairs were previously identified (Jewell et al., 2015) as divergent in DMI at similar levels of ECM production over 3 discrete ranges of DIM (76-82, 151-157, and 251-257 DIM) over both their first and second lactations. At the start of the present experiment, the 6 cows were allocated to 3 pairings, each containing 1 cow with high $\operatorname{MPE}(\mathbf{H E})$ and 1 with low MPE (LE) based on the previous determinations (see Figure 1 of Jewell et al., 2015). The cows were offered the same TMR once daily at $\sim 0900 \mathrm{~h}$ to achieve $\sim 10 \%$ refusals. The ration was formulated to meet NRC guidelines for high-producing dairy cows (NRC, 2001), and contained (per $\mathrm{kg}$ of DM): $277 \mathrm{~g}$ of corn silage, $244 \mathrm{~g}$ of finely ground high-moisture shell corn, $265 \mathrm{~g}$ of alfalfa silage, $84 \mathrm{~g}$ of canola meal, $76 \mathrm{~g}$ of roasted soybeans, $41 \mathrm{~g}$ of distillers dried grains, and $25 \mathrm{~g}$ of vitamin/mineral mix. Upon analysis the ration contained (per $\mathrm{kg}$ of DM) $288 \mathrm{~g}$ of NDF (including 208 $\mathrm{g}$ of ADF and $26.7 \mathrm{~g}$ of ADL), $440 \mathrm{~g}$ of NFC (including $267 \mathrm{~g}$ of starch), $55 \mathrm{~g}$ of fat (ether extract), and $169 \mathrm{~g}$ of CP. The DMI (feed presented minus residual feed at the next feeding) and milk yields ( $\mathrm{kg}$ ) were determined daily, and milk samples were collected at each of 3 milkings on all days between -8 and $+7 \mathrm{~d}$ relative to the date of ruminal contents exchange, and at each ruminal sampling day between 10 and $56 \mathrm{~d}$ postexchange (see below).

\section{Ruminal Contents Exchange}

Just before the morning feeding (February 10, 2015), ruminal contents were almost completely (subjectively estimated at $\sim 95 \%$ ) removed from each cow through the ruminal cannula, and transferred to a tared container. Fluid-saturated solid digesta were first removed by handfuls, and finally liquid was removed using a small $(\sim 100 \mathrm{~mL})$ cup. Care was taken to locate and at least partially empty folds and pockets within the rumen to increase the extent of digesta removal, but with the intent of leaving a small fraction of the microbiome behind to serve as competitors for the introduced inoculum, as described previously (Weimer et al., 2010a). The solids, liquids, and tared bin were weighed. As soon as both rumens within a pair of cows were emptied, the contents were transferred between 
cows by manually hand-stuffing (solids) and finally pouring (remaining liquids) the digesta from 1 cow into the other of the pair. The time required for emptying and refilling each rumen was $\sim 25$ to $30 \mathrm{~min}$, and the total amounts transferred varied from $\sim 66$ to $\sim 96 \mathrm{~kg}$ (Table 1). The amounts of ruminal contents removed (wet basis) represented 9.7 to $12.5 \%$ of the mean BW of each cow.

\section{Ruminal Sampling}

Measurements of $\mathrm{pH}$ and ruminal sample collections were performed just before feeding to maintain consistency with sample timing in the study of Jewell et al. (2015) that was used to identify the cows selected for ruminal contents exchange. Ruminal liquid- and solids-associated samples were collected on $\mathrm{d}-8$, $-7,-5,-4$, and -1 (before exchange); immediately before exchange (d 0 pre); $\sim 1 \mathrm{~h}$ after exchange (d 0 post); and just before feeding on d 1, 2, 3, 7, 10, 14, $21,28,35,42$, and 56 after exchange. This asymmetric sampling schedule was employed for logistical reasons (labor availability during the work week) and the desire to maximize sampling frequency during the first $3 \mathrm{~d}$ following the exchange, during which we expected the greatest changes in bacterial community composition (BCC) to occur (Weimer et al., 2010a). The epimural (rumen-epithelial associated) community was not examined because we could not perform an exchange of this community between cows. Sampling was conducted as follows. First, ruminal $\mathrm{pH}$ was measured by direct insertion of a $\mathrm{pH}$ probe (connected to a model 340i portable pH meter; WTW, Weinheim, Germany) into the medio-ventral region of the rumen. The ruminal contents were hand mixed during the $\mathrm{pH}$ measurement, and afterward ruminal liquid and solids were removed from the medio-ventral region of the rumen using a sampling cup $(\sim 100 \mathrm{~mL})$. The sample was immediately

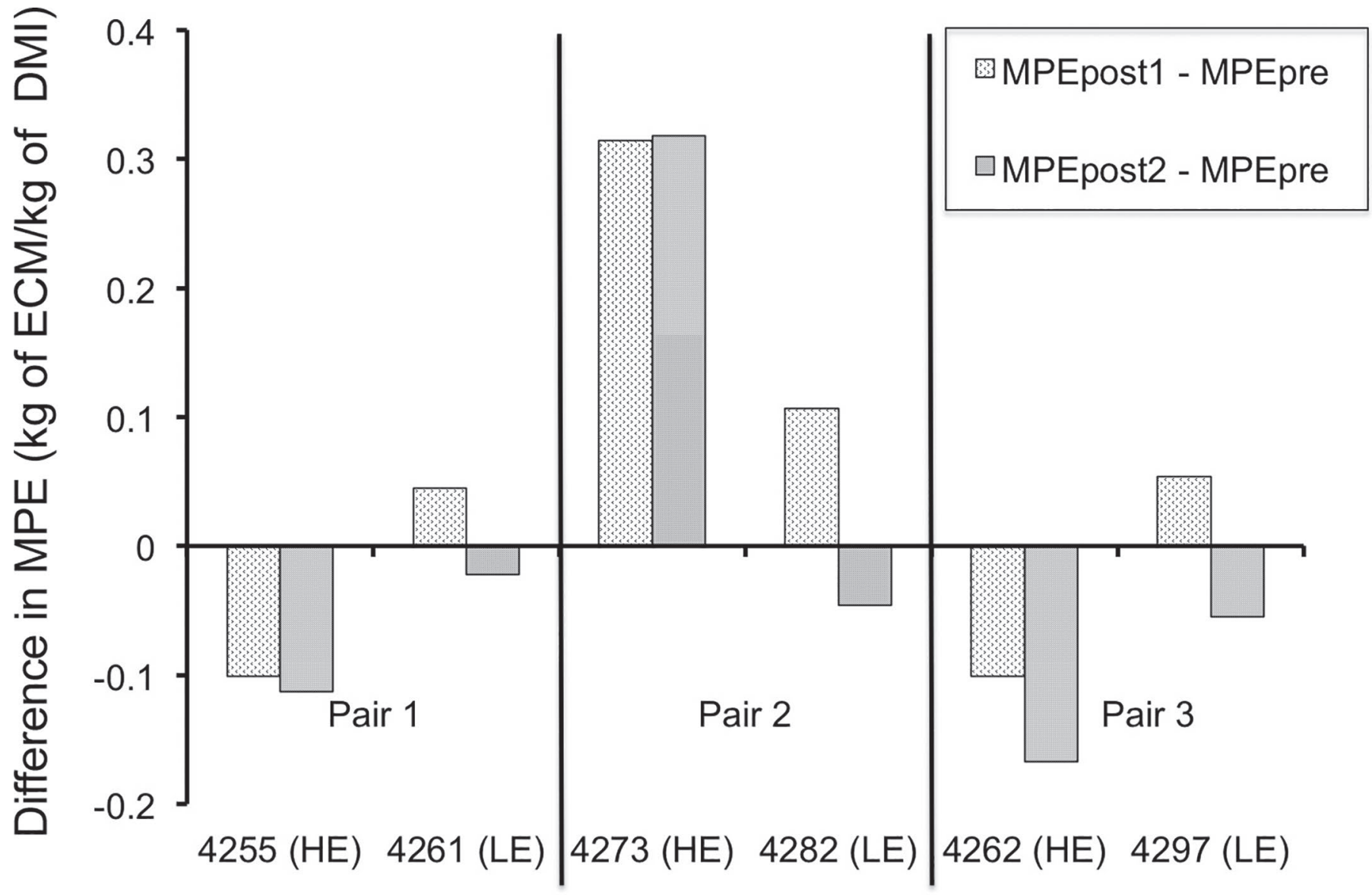

Figure 1. Differences in milk production efficiency (MPE; $\mathrm{kg}$ of ECM per $\mathrm{kg}$ of DMI, ECM/DMI) between the preexchange period (Pre) and postexchange period 1 (Post1, 1 to $7 \mathrm{~d}$ after exchange), and between the preexchange period and postexchange period 2 (Post2, 10 to 56 d after exchange. Each bar represents a single calculation from the summed values of ECM and DMI within the sampling period, to minimize variability in daily MPE measurements. Cows are denoted by identification number and efficiency status [high efficiency (HE) or low efficiency (LE)] and are grouped by cow pair (within-pair equivalence of ECM). 
and tightly hand-squeezed through 4 layers of cheesecloth, and separate samples of filtered liquid $(\sim 45 \mathrm{~mL})$ and solids ( $\sim 50 \mathrm{~mL}$ packed volume) were placed in $50-$ $\mathrm{mL}$ conical plastic centrifuge tubes (Corning, Oneonta, NY) that were immediately packed in ice before laboratory storage at $-80^{\circ} \mathrm{C}$.

\section{Analyses}

Individual VFA and lactate in ruminal liquid samples were determined by HPLC (Weimer et al., 1991). Milk composition (fat, protein, lactose, milk urea nitrogen, and SCC) was determined by near-infrared spectroscopy (AgSource, Verona, WI, Foss FT6000 instrument, Foss Electric, Hillerod, Denmark; method 972.16; AOAC, 1990). Energy-corrected milk (kg) was calculated at each milking from milk yield and milk composition, using the formula of Tyrrell and Reid (1965), and was summed by day. Milk production efficiency (defined as $\mathrm{kg}$ of ECM produced $/ \mathrm{kg}$ of DMI) was calculated both by day and over discrete periods (indicated in the Results) from the total ECM produced on a given day and the total DMI consumed over the previous day.

\section{Milk Production Efficiency Statistical Analysis}

Determination of changes in MPE were focused on within-cow changes rather than differences between cows in a pair. This approach was taken because of challenges in interpreting changes in MPE over time within this experiment. Unlike the study in which these cow pairs divergent in MPE were originally identified (Jewell et al., 2015), and in which ECM/DMI could be calculated for each cow over the same discrete ranges of DIM within the lactation cycle, the cows within each pair in the current experiment differed in DIM at the start of the experiment. Thus the cows within each pair differed in stage of lactation and cannot be simply compared with one another with respect to ECM/DMI. As indicated in Table 1, one cow (4297) was just past peak lactation $(\mathrm{DIM}=79)$ at the time of the contents exchange, whereas the other 5 were substantially past peak lactation (DIM $>120 \mathrm{~d}$ ), and for these cows MPE would be expected to decline gradually and possibly at different rates over time. To address this, we tested for changes in MPE for each cow in 3 different ways. First, we calculated 3 separate MPE values $\left(\mathbf{M P E}_{\text {Pre }}\right.$, $\mathbf{M P E}_{\text {Post1 }}$, and $\left.\mathrm{MPE}_{\text {Post2 }}\right)$ for each cow to describe mean performance in each of the 3 time periods relative to the date of contents exchange: -8 to $0 \mathrm{~d}$ (Pre), 1 to $7 \mathrm{~d}$ (Post1), and 8 to $56 \mathrm{~d}$ (Post2). The MPE data were analyzed to detect transient changes in MPE that may have occurred immediately after contents ex- change, before the resilience of the ruminal community might return the bacterial community to resemble its original composition (Weimer et al., 2010a). Differences between Pre and Post1 and Post2 values of DMI, ECM, and MPE for individual cows within MPE status (HE or LE, $\mathrm{n}=3$ in each test) were evaluated for outliers using the Dixon Q test (Rorabacher, 1991). For each cow, least squares means were compared across period (Pre, Post1, Post2) using PROC MIXED in SAS version 9.2 (SAS Institute Inc., Cary, NC). Second, we analyzed each MPE status (HE or LE, $\mathrm{n}=3$ in each test) separately using $t$-tests to determine whether the values of $\mathrm{MPE}_{\text {Post1 }}$ minus $\mathrm{MPE}_{\text {Pre }}$ and of $\mathrm{MPE}_{\text {Post2 }}$ minus $\mathrm{MPE}_{\text {Pre }}$ differed from zero. Third, despite known uncertainties regarding very short-term MPE measurements (Connor et al., 2012), within each cow we calculated MPE for each day and performed a regression analysis of this daily MPE versus sampling day through the daily data of the Pre and Post2 periods (i.e., excluding the Post1 period) using PROC CORR in SAS, and then examined the departure from the regression line (observed daily MPE minus regression-predicted daily MPE) for each day during the Post1 period (i.e., the first $7 \mathrm{~d}$ after the contents exchange). These daily residual MPE values (observed minus predicted for the Post1 period; $\mathrm{n}=7$ for each cow) within group (HE or LE) were analyzed by a $t$-test to determine if they were significantly different from zero (i.e., if MPE was higher or lower during period Post1 than predicted by the regression line).

To examine the relationship between MPE and ruminal VFA, the total millimolar VFA concentration and the molar percentage of each individual VFA were each compared between HE and LE cows using PROC MIXED in SAS with MPE status (high or low) and period (Pre, Post1, and Post2) as independent variables along with MPE status-by-period interaction; when the interaction term was not significant $(P>$ 0.1 ), it was removed from the model. In addition, total VFA concentration and the molar percentage of each individual VFA were examined within each cow pair to determine the effect of the exchange on these variables across periods.

\section{DNA Isolation}

Liquid and solid samples of ruminal contents stored at $-80^{\circ} \mathrm{C}$ were thawed in a water bath at room temperature, then processed separately to isolate DNA, as described previously (Stevenson and Weimer, 2007). This procedure is very similar to the PSCA method of Henderson et al. (2013), who showed that the PSCA method produced the highest yield of microbial DNA of 13 methods tested, and was likely the most representative of the microbial community. The DNA obtained 
was resuspended in $10 \mathrm{~m} M$ Tris $\mathrm{HCl}$ with $1 \mathrm{~m} M$ EDTA ( $\mathrm{pH}$ 8.0), quantified fluorometrically using a Qubit (Invitrogen, Carlsbad, CA), and stored at $4^{\circ} \mathrm{C}$ before preparation of the DNA library.

\section{Amplification and Sequencing of Bacterial 16S rRNA Genes}

Universal primers flanking the variable 4 region of the bacterial 16S rRNA coding region were used to perform PCR, one reaction per sample (Kozich et al., 2013). A total of $50 \mathrm{ng}$ of DNA, 5 pmol of each primer, and $12.5 \mu \mathrm{L}$ of $2 \mathrm{X}$ HotStart ReadyMix (KAPA Biosystems, Wilmington, MA), and water to a total volume of $25 \mu \mathrm{L}$ were used. Cycling conditions were as follows: initial denaturation of $95^{\circ} \mathrm{C}$ for $3 \mathrm{~min}, 25$ cycles of $95^{\circ} \mathrm{C}$ for $30 \mathrm{~s}, 55^{\circ} \mathrm{C}$ for $30 \mathrm{~s}$, and $72^{\circ} \mathrm{C}$ for $30 \mathrm{~s}$, and a final extension at $72^{\circ} \mathrm{C}$ for $5 \mathrm{~min}$. Gel electrophoresis was performed using a 1.0\% low-melt agarose gel (National Diagnostics, Atlanta, GA), and amplified DNA was extracted from the gel using a ZR-96 Zymoclean Gel DNA Recovery Kit (Zymo Research, Irvine, CA). Extracted DNA was quantified in duplicate on 96-well microplates according to manufacturer's instructions for the Quant-iT dsDNA Broad-Range Assay Kit, using reagents from a Qubit dsDNA Assay Kit (Thermo Fisher Scientific, Waltham, MA), read on a Synergy 2 Multi-Mode Reader (BioTek, Winooski, VT) after a programmed 3-s shaking period and a 2-min incubation at $22^{\circ} \mathrm{C}$. The extracted DNA was equimolar pooled, combined with a 5 to $10 \%$ PhiX control DNA, and then was sequenced as paired-end reads, 250 cycles each $(2$ $\times 250$ ) using the MiSeq $2 \times 250$ v2 or MiSeq $2 \times 300$ v3 kit for liquid samples (Illumina, San Diego, CA) with custom sequencing primers as described by Kozich et al. (2013). All sequences from this project have been deposited in the National Center for Biotechnology Information Short Read Archive under the accession number SRP078610.

\section{Sequence Cleanup}

Sequences were demultiplexed according to their sample-specific indices on the Illumina MiSeq. The program mothur v.1.36.1 was used for further processing (Schloss et al., 2009), following a protocol developed from Kozich et al. (2013), accessed January 2016 (Supplemental Text 1; https://doi.org/10.3168/ jds.2017-12746). Paired-end sequences were combined to form contigs and poor quality sequences were removed (e.g., elimination of sequences with ambiguous base pairs, homopolymers greater than $8 \mathrm{bp}$, sequences shorter than $200 \mathrm{bp}$ ). The SILVA $16 \mathrm{~S}$ rRNA gene reference alignment database v119 (Pruesse et al., 2007) was used to screen for alignment to the correct region. Preclustering was performed (diffs $=2$ ) to reduce error and chimeras were detected and removed (UCHIME; Edgar et al., 2011). The GreenGenes database (DeSantis et al., 2006), August 2013 release, was used to classify sequences with a bootstrap value cutoff of 80 . Sequences classified to cyanobacteria, mitochondria, Eukarya, or Archaea were removed. Singletons were removed to streamline analysis.

\section{Sequence Analysis and Statistical Analysis}

Bacterial sequences were grouped into operational taxonomic units (OTU) with 97\% sequence similarity. Good's coverage (Good, 1953) was calculated in mothur for all samples. The OTU counts were normalized to 10,000 sequences per sample, and the normalized counts of OTU by sample were used for further analysis. Alpha diversity (community diversity within individual animals within each period) was assessed using Chao's estimate of species richness (Chao, 1984) and Shannon's diversity index (Shannon, 2001). Differences in community diversity and richness between animals of a given efficiency in a given time window of the study were assessed by overall 2-way ANOVA, and pairwise by $t$-test using false discovery rate (FDR) correction for multiple comparisons in R v3.2.1 (R Development Core Team, 2011).

Beta diversity (differences in community composition between samples) was assessed by using nonmetric multidimensional scaling to visualize differences between samples calculated as the Bray-Curtis metric (Bray and Curtis, 1957) with square-root-transformed data in $\mathrm{R}$ (vegan, Okansen et al., 2016). Changes in total community structure (relative abundance, Bray-Curtis metric) and composition (presence/absence, Jaccard metric; Jaccard, 1912) were assessed using permutational multivariate ANOVA in $\mathrm{R}$ (vegan). Samples were assessed by initial efficiency and categorical time within the observation period (Pre: -8 to $0 \mathrm{~d}$, Post1: 0 to $7 \mathrm{~d}$, and Post2: 10 to $56 \mathrm{~d}$ ), with permutations stratified within each coupled pair of animals. Pairwise comparisons between each group were quantified with Permutational Multivariate ANOVA, and $P$-values FDR-corrected. $\mathrm{R}$ code is shown in Supplemental Text 2 (https://doi. org/10.3168/jds.2017-12746).

\section{RESULTS}

\section{Production}

Day-to-day variation in DMI, milk yield, and milk composition, along with natural changes in MPE over the course of the lactation cycle, make difficult the task 
of identifying short-term trends in MPE that might have resulted from ruminal contents exchange. These difficulties are exacerbated by the fact that all 6 cows were, to varying extents, past peak lactation and thus could be expected to decline in both production and efficiency, but at variable rates. By breaking the production data into 3 periods (Pre, Post1, and Post2), we observed numeric differences in MPE between periods $\left(\mathrm{MPE}_{\text {Pre }}, \mathrm{MPE}_{\text {Post1 }}\right.$ and $\left.\mathrm{MPE}_{\text {Post2 }}\right)$ within individual cows, but most differences were not significant (Table 2 ). Despite the general decline in MPE over time, all 3 of the LE cows within each pair displayed a numerically transient increase in MPE during the week following the contents exchange with the higher MPE partner (Table 2 ). The trends for the HE cows were more equivocal. For 2 of the HE cows, MPE numerically declined in the first week after the exchange (i.e., after introduction of the LE community) and declined further over the remainder of the experiment (10 to $56 \mathrm{~d}$ postexchange). However, the third HE cow (4273) displayed an increase in MPE after replacement of digesta with that from its LE partner, which was retained over the 8-wk postexchange experiment; this increase in MPE with increasing DIM late in lactation is highly atypical in dairy cows (Linn et al., 2007; Jewell et al., 2015).

The direction of changes in MPE that occurred following contents exchange was more clearly demonstrated a second analysis that compared differences between $\mathrm{MPE}_{\mathrm{Pre}}$ and $\mathrm{MPE}_{\text {Post1 }}$ and differences between $\mathrm{MPE}_{\text {Pre }}$ and $\mathrm{MPE}_{\text {Post2 }}$, calculated using the total ECM and DMI measured during each period (Figure 1). The MPE showed an increase in LE cows (mean $=+0.069$; differs from $0, P=0.07, \mathrm{n}=3$ ) after digesta transfer in period Post1, and (as expected for late-lactation cows) a decline during the Post2 period (mean $=-0.041$; differs from $0, P=0.05, \mathrm{n}=3$ ). No significant differences were found with all $3 \mathrm{HE}$ cows used in the analysis of the differences between the post periods and the pretransfer period (differs from $0, P>0.80, \mathrm{n}=3$ ). As is evident from Figure 1, HE cow 4273 had a pattern and magnitude of MPE response that differed grossly from those of all the other cows; its cause was not obviously attributable to dietary or management factors. As a result, mean MPE also increased numerically by 0.033 in the HE group during the Post1 period and by 0.014 in the Post2 period (though it changed by an average of -0.101 and -0.140 , respectively, in the other $2 \mathrm{HE}$ cows). However, the difference in DMI between Pre and Post1 for Cow 4273 was determined to be an outlier in the HE group $(P<0.05, \mathrm{n}=3)$. The $2.6 \mathrm{~kg}$ of DMI decline for 4273 between Pre and Post1 compared with the $1 \mathrm{~kg}$ increase in DMI for the other $2 \mathrm{HE}$ cows after transfer affected the denominator of MPE. Cow 4273 was also an outlier in the HE group for the difference in MPE between Pre and Post1 $(P<0.01, \mathrm{n}=3)$, with an increase of 0.314 compared with the decline of 0.101 for both of the other HE cows. Analysis of the HE cows without cow 4273 based on her status as an outlier showed declines in MPE in Post1 relative to the pretransfer period (Post1 mean $=-0.101$; differs from $0, P<0.001)$. No other outliers were detected in HE or LE groups.

To examine the effects of time and contents exchange in a manner that takes into account the decrease in MPE over time, we performed regression analysis (Table 3) on the MPE data for individual cows across periods. Changes in MPE for individual cows during period Post1were visually observable as a daily departure from the ECM/DMI regression line constructed from the data points of periods Pre and Post2 (i.e., between -8 to 0 , and 10 to $56 \mathrm{~d}$ ) for that cow (Figures 2 and 3). During the week following contents exchange, most of the daily MPE values for the LE cows that received the ruminal community from their HE pair-

Table 2. Milk production efficiency (MPE) of cows before and after near-total exchange of ruminal contents

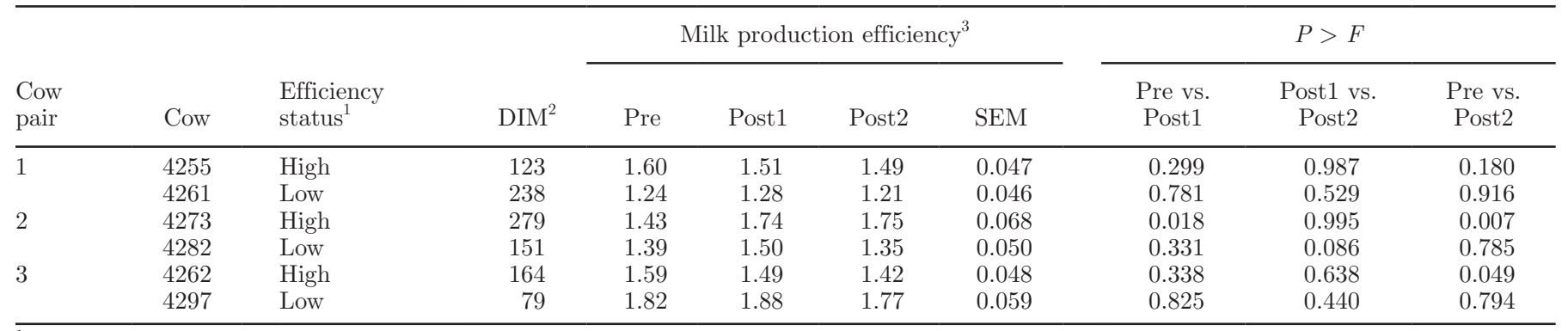

\footnotetext{
${ }^{1}$ Milk production efficiency status (low = less efficient; high = more efficient) based on differences in MPE within pair at the same level of ECM production, determined in 2 previous lactations (see text).

${ }^{2}$ Days in milk on day of ruminal contents exchange.

${ }^{3}$ Milk production efficiency during indicated time period, calculated as kilograms of ECM per kilogram of DMI. Periods: Pre $=8 \mathrm{~d}$ before exchange to day of exchange; Post1 $=\mathrm{d} 1$ to 7 after exchange; Post $2=\mathrm{d} 10,14,21,28,35,42$, and 56 after exchange.
} 
mate were displaced above the regression line, with an average daily MPE change of $+0.079 \pm 0.033(P>|\mathrm{t}|$ $=0.027$ ), indicative of a transient but significant increase in MPE during the week following the exchange. The results for the HE cows were more equivocal. Two of the $3 \mathrm{HE}$ cows (4255 and 4261) that received the LE transfer generally displayed more MPE values displaced below their respective regression line than above the line, whereas the atypical HE cow (4273) increased her MPE across measurement periods before and after contents exchange. For the HE cows that received the LE digesta, the daily MPE increased by an average of $0.032 \pm 0.039$ across all 3 cows $(P>|\mathrm{t}|=0.42)$, but this increase was solely due to atypical cow 4273 (the other 2 cows averaged a daily MPE change of -0.052 $\pm 0.004, P>|\mathrm{t}|=0.106)$. Moreover, the high relative error introduced by cow 4273 resulted in an overall nonsignificant difference in residual MPE between the $\mathrm{HE}$ and LE groups. Averaging of daily residuals over successive days starting at $\mathrm{d} 1$ after exchange (Figure 3 ) revealed different patterns for the $\mathrm{HE}$ and LE cows. The HE cows 4255 and 4262 displayed a positive slope for these averaged residuals over time, indicating a recovery of MPE lost immediately after contents exchange, whereas the opposite effect was only seen in one of the LE cows (cow 4261). Separate analysis of the ECM and DMI data (Supplemental Table S1; https://doi. org/10.3168/jds.2017-12746) revealed that the former changed relatively little across periods, whereas DMI changes were often significant, and thus were primarily responsible for changes in MPE over time.

\section{Ruminal Chemistry}

Ruminal chemistry data included pH (measured directly in the rumen) and the concentrations and molar percentages of VFA and lactate in the same ruminal liquid phase samples collected for bacterial community analysis $(\mathrm{n}=6$ per cow before contents exchange, and $\mathrm{n}$ $=12$ per cow after contents exchange, total samples $=$ 108), with all samples collected just before feeding (and additionally, on d 0 , just before contents exchange).

Ruminal $\mathrm{pH}$ data are summarized in Supplemental Figure S1 (https://doi.org/10.3168/jds.2017-12746). For cow pairs 1 and 3 , prefeed $\mathrm{pH}$ did not differ between pairs before or after contents exchange $(P>$ 0.52 for all comparisons). For cow pair $2, \mathrm{pH}$ differed numerically $(P=0.13, \mathrm{n}=6)$ before the exchange, and significantly both after contents exchange $(P=0.002$, $\mathrm{n}=11)$ and across periods $(P=0.003, \mathrm{n}=17)$. Within this cow pair, prefeed ruminal $\mathrm{pH}$ resembled that of the donor cow immediately after the exchange (d 0 post), but returned to that of the recipient cow within $1 \mathrm{~d}$ of contents exchange. For all 6 cows, prefeed $\mathrm{pH}$ after contents exchange did not differ from the prefeed $\mathrm{pH}$ before the exchange for that cow (mean difference $=$ 0.03, range 0 to 0.08, SEM $=0.04$; Supplemental Figure S1; https://doi.org/10.3168/jds.2017-12746).

For each cow, exchange of ruminal contents was accompanied by a slight numeric (nonsignificant) decrease in prefeed total VFA concentration (Pre vs. Post1, Table 4). The ratio [(mean prefeed total VFA concentrations for d 1 samples)/(mean prefeed total VFA concentration during the preexchange period)] for the 6 cows was $105.0 \mathrm{mM} / 105.1 \mathrm{~m} M$, or 0.999 . For individual cows, this ratio ranged from 0.794 to 1.114. These data suggest that the process of contents exchange (during which transient cooling and air exposure of the exchanged microbiota occurred) did not negatively affect the ability of the microbiota to ferment feeds to VFA upon reinsertion into the rumen. For the HE cows, the molar percentage of acetate and butyrate increased numerically during the week following exchange, but decreased for the LE cows. None of the differences in VFA concentrations or proportions were significant $(P>0.05)$. As in the case of prefeed $\mathrm{pH}$, the

Table 3. Regression analysis of milk production efficiency (MPE) before and after ruminal contents exchange

\begin{tabular}{lllcrcr}
\hline $\begin{array}{l}\text { Cow } \\
\text { pair }\end{array}$ & Cow & $\begin{array}{l}\text { Efficiency } \\
\text { status }^{1}\end{array}$ & $\begin{array}{c}\text { Regression equation for } \\
\text { MPE versus day }\end{array}$ & $\begin{array}{c}\mathrm{R}^{2} \text { of } \\
\text { regression line }\end{array}$ & $\begin{array}{c}P>F \text { of } \\
\text { regression line }\end{array}$ & $\begin{array}{c}\text { Mean departure from } \\
\text { regression line, } \mathrm{d} 1 \text { to } 7^{3}\end{array}$ \\
\hline 1 & 4255 & High & $1.58870-(0.0033320 \times$ day $)$ & 0.236 & 0.066 & -0.056 \\
& 4261 & Low & $1.22556-(0.0001139 \times$ day $)$ & 0.0005 & 0.935 & +0.052 \\
2 & 4273 & High & $1.48334+(0.0084000 \times$ day $)$ & 0.546 & 0.002 & +0.200 \\
& 4282 & Low & $1.34711-(0.0009323 \times$ day $)$ & 0.066 & 0.377 & +0.109 \\
3 & 4262 & High & $1.53150-(0.0020000 \times$ day $)$ & 0.086 & 0.288 & -0.048 \\
& 4297 & Low & $1.79723-(0.0002754 \times$ day $)$ & 0.001 & 0.899 & +0.071 \\
\hline
\end{tabular}

\footnotetext{
${ }^{1}$ Milk production efficiency based differences in DMI within pair at same level of ECM production, in 2 previous lactations (Jewell et al., 2015; see text).

${ }^{2}$ Regression line derived from daily MPE ( $\mathrm{kg}$ of ECM/kg of DMI) data before contents exchange (d -8 to -1 ), and d 10, 14, 21, 28, 35, 42, and 56 after exchange. Day in formula is relative to date of ruminal contents exchange.

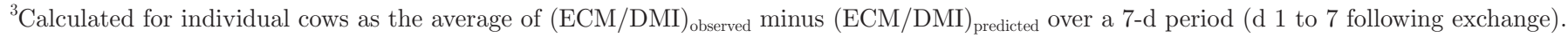



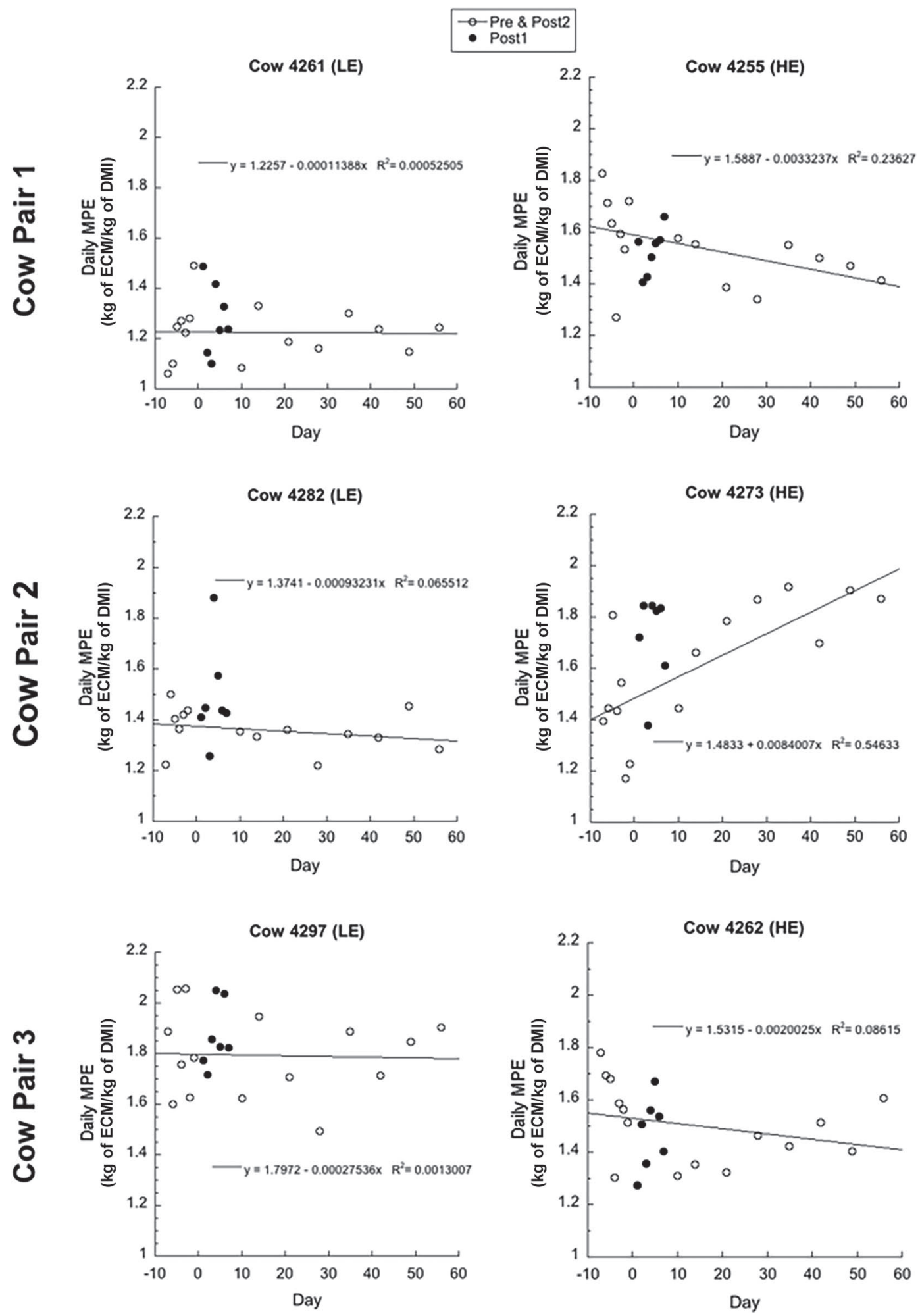

Figure 2. Daily variation in calculated milk production efficiency (MPE; kg of ECM per kg of DMI, ECM/DMI). For each cow of higher or lower efficiency (HE and LE, respectively) within a pair, a regression line was constructed for daily MPE values (open circles) over the range of -8 to $0 \mathrm{~d}$ before, and 10 to $56 \mathrm{~d}$ after, ruminal contents exchange. Daily MPE values during the week following contents exchange are represented as closed circles. Data points above or below the regression line are indicative of a transient increase or decrease, respectively, in MPE, relative to that predicted by the regression equation. Pre $=8 \mathrm{~d}$ before exchange to day of exchange; Post1 $=\mathrm{d} 1$ to 7 after exchange; Post $2=$ d $10,14,21,28,35,42$, and 56 after exchange. 
prefeed concentrations of total VFA and mol\% of the predominant VFA (acetate, propionate, and butyrate) resembled their preexchange values more closely than
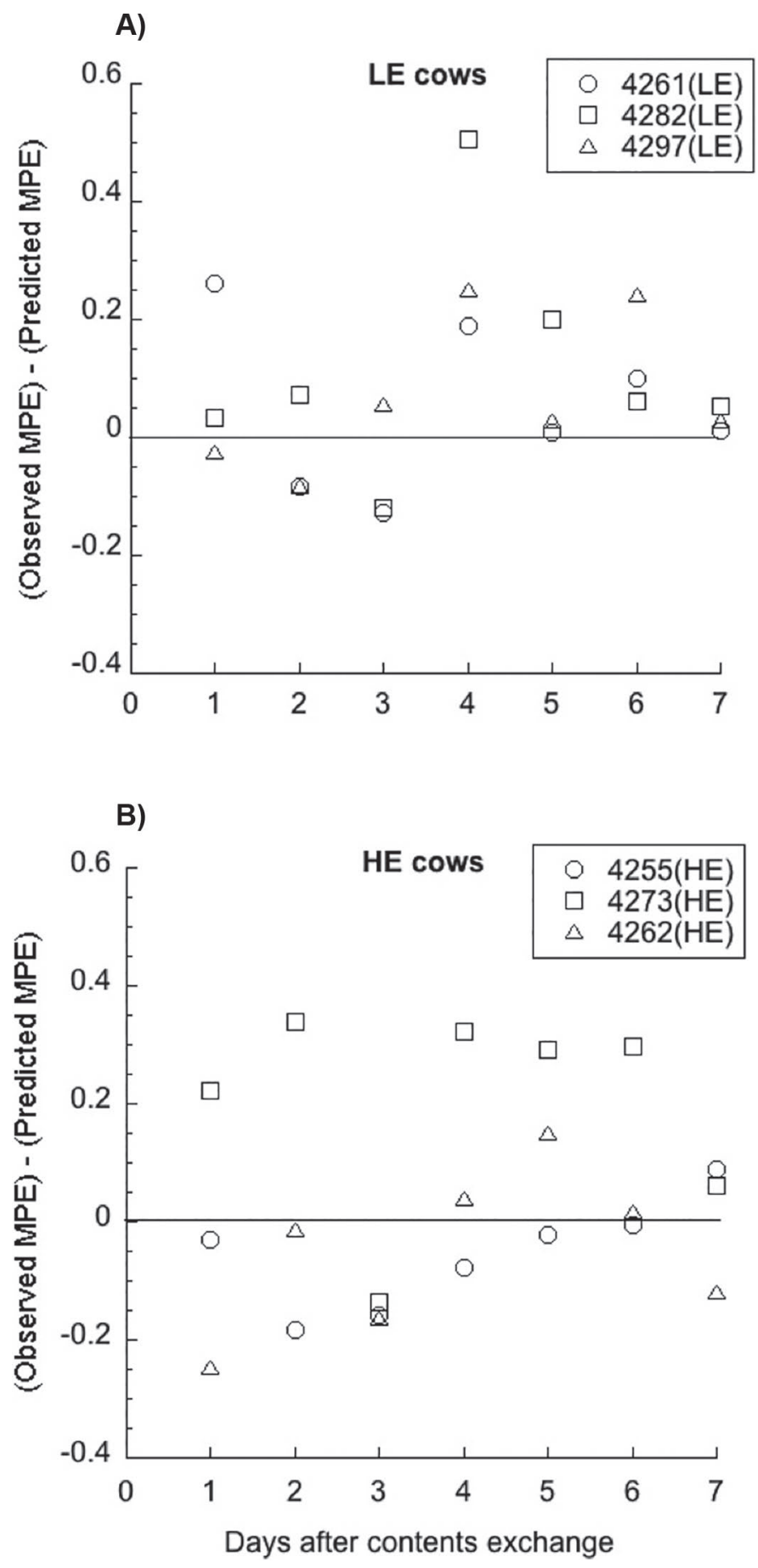

Figure 3. Mean of residuals [observed daily milk production efficiency (MPE) minus predicted daily MPE from the regression equations in Table 3] over the week following ruminal contents exchange. Each data point was calculated as the mean of all daily residuals between $\mathrm{d} 1$ and the indicated day postexchange. $\mathrm{HE}=$ high efficiency; $\mathrm{LE}=$ low efficiency. they did those of the donor cow's preexchange values. Lactate was not detected in any of the prefeed samples.

When analyzed by efficiency group, the total concentration of ruminal VFA, as well as the molar percentage of individual VFA, differed between the high and low MPE cows (Table 5). The HE cows displayed higher total VFA concentrations, and higher proportions of odd-chain-length VFA (propionate and valerate) but a lower proportion of even-chain-length VFA (acetate and butyrate).

\section{Sequencing Coverage}

All ruminal liquid and solid digesta samples $(\mathrm{n}=108$ each, see Ruminal Sampling section above) were used to assess $\mathrm{BCC}$ by next-generation sequencing of the variable 4 region of $16 \mathrm{~S}$ rRNA genes. After sequence cleanup in mothur, 8.1 million total high-quality bacterial sequences were obtained (average per sample 37,502 $\pm 2,527 \mathrm{SEM}$ ). Good's coverage was greater than $97 \%$ for all samples (Supplemental Data Sheet 1; https:// doi.org/10.3168/jds.2017-12746).

\section{Alpha Diversity}

Two-way ANOVA revealed that, in general, ruminal solids had higher community diversity (Shannon's) than did ruminal liquids $\left(F_{1,204}=93.69, P<0.001\right)$, and LE cows had higher diversity than did HE cows $\left(F_{1,204}=32.06, P<0.001\right.$, Figure 4$)$. The effect of time period on community diversity was different between the $2 \mathrm{MPE}$ groups $\left(F_{2,204}=4.33, P=0.014\right)$. Generally, HE cows displayed increased bacterial diversity in the Post1 period ( $0-7 \mathrm{~d})$, and returned to preexchange diversity in Post2 (10-56 d), whereas LE cows displayed decreased diversity in Post1 before returning to preexchange levels. The effect of ruminal contents phase on diversity was also dependent on MPE group $\left(F_{2,204}=3.89, P=0.050\right)$, with the difference between solid and liquid samples being more pronounced in HE than in LE cows. However, few pairwise comparisons across sampling period within ruminal contents phase were significant (Supplemental Data Sheet 2; https:// doi.org/10.3168/jds.2017-12746).

Two-way ANOVA also revealed that community richness (Chao 1) was generally greater in solids than liquids $\left(F_{1,204}=83.46, P<0.001\right)$, and was greater in LE cows than in HE cows $\left(F_{1,204}=5.51, P=0.020\right.$, Figure 4). Response of richness to sampling time was different between the MPE groups $\left(F_{2,204}=3.82, P=0.024\right)$, with richness in the HE cows increasing between Pre and Post1 then returning to Pre levels in Post2, and LE cows showing no overall change in richness over time. The effect of sampling time on richness was dependent 
Table 4. Least squares means of ruminal VFA profiles in cows before and after near-total exchange of ruminal contents

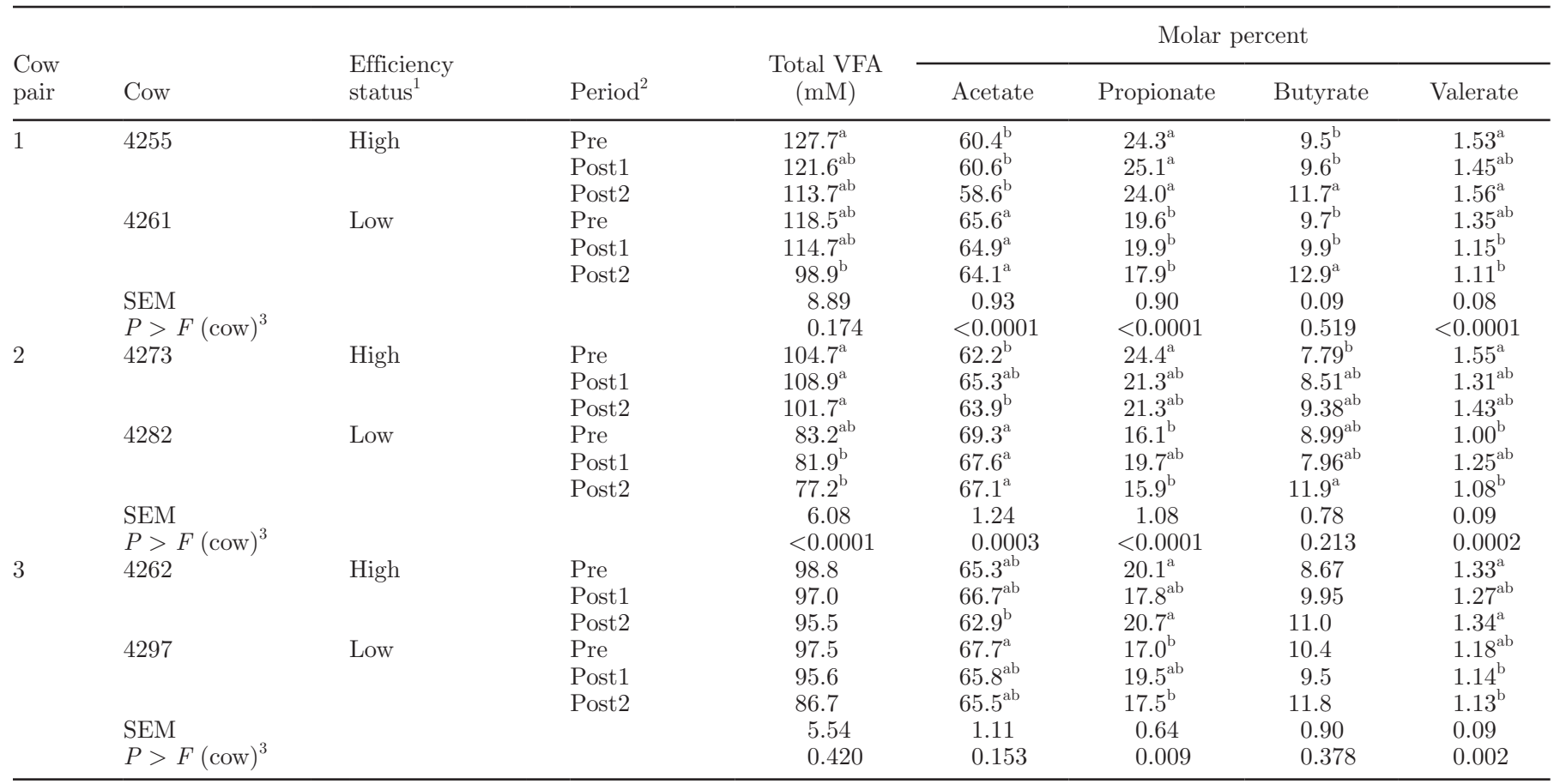

${ }^{\mathrm{a}, \mathrm{b}}$ Values having different superscripts within a column differ $(P<0.05)$ in comparisons across all periods for the specific cow pair.

${ }^{1}$ See text for description of milk production efficiency status.

${ }^{2}$ Ruminal liquid samples collected just before feeding during period Pre before exchange $(\mathrm{d}=-8,-7,-5,-4,-1,0)$, or during periods Post1 (d $=1,2,3,7$ after exchange) or Post2 $(\mathrm{d}=10,14,21,28,35,42,56$ after exchange).

${ }^{3}$ Comparisons between cows within a pair across all periods.

on sample type $\left(F_{2,204}=3.84, P=0.023\right)$, with richness in the ruminal liquids remaining unchanged for both $\mathrm{HE}$ and LE cows over the course of the study. Richness in the ruminal solids generally increased in HE cows, but in LE cows richness decreased from Pre to Post1, then returned to preexchange state in Post2. However, few pairwise comparisons across sampling period within ruminal contents phase were statistically significant (Supplemental Data Sheet 2; https://doi.org/10.3168/ jds.2017-12746). Thus, for both diversity and richness, overall differences were present between sample types and between MPE status groups, but little discernible change within cows across periods.

\section{Beta Diversity}

Patterns of change in BCC over time between cows within pairs were apparent when analyzed using nonmetric multidimensional scaling plot of the Bray-Curtis dissimilarity metric, as visualized using ellipses dis-

Table 5. Concentrations and proportions of VFA in liquid phase of ruminal contents of high milk production efficiency (HE) cows and low milk production efficiency (LE) cows, averaged across periods for all prefeed ruminal samples (excluding sample collected immediately after contents exchange)

\begin{tabular}{lcccc}
\hline & \multicolumn{2}{c}{ LSM } & & \\
\cline { 2 - 3 } Variable & HE cows & LE cows & & SEM \\
\hline mM total VFA & 108.2 & 94.9 & 2.72 & $P>F$ \\
Mol \% acetate & 62.8 & 66.4 & 0.45 & $<0.0006$ \\
Mol \% propionate & 22.4 & 18.1 & 0.37 & $<0.0001$ \\
Mol \% butyrate & 9.53 & 10.2 & 0.30 & 0.045 \\
Mol \% valerate & 1.45 & 1.15 & 0.03 & $<0.0001$ \\
Mol \% isobutyrate & 0.75 & 0.79 & 0.04 & 0.333 \\
Mol \% isoval+2MB & 3.31 & 3.29 & 0.08 & 0.791 \\
\hline
\end{tabular}

${ }^{1}$ Isovalerate plus 2-methylbutyrate, which co-eluted in the HPLC analysis. 
playing 95\% confidence intervals (Figure 5; individual data points are displayed in Supplemental Figure S2; https://doi.org/10.3168/jds.2017-12746). Bray-Curtis- measured community composition differed significantly between solid and liquid samples (permutational multivariate ANOVA, $P<0.001$, Supplemental Data Sheet
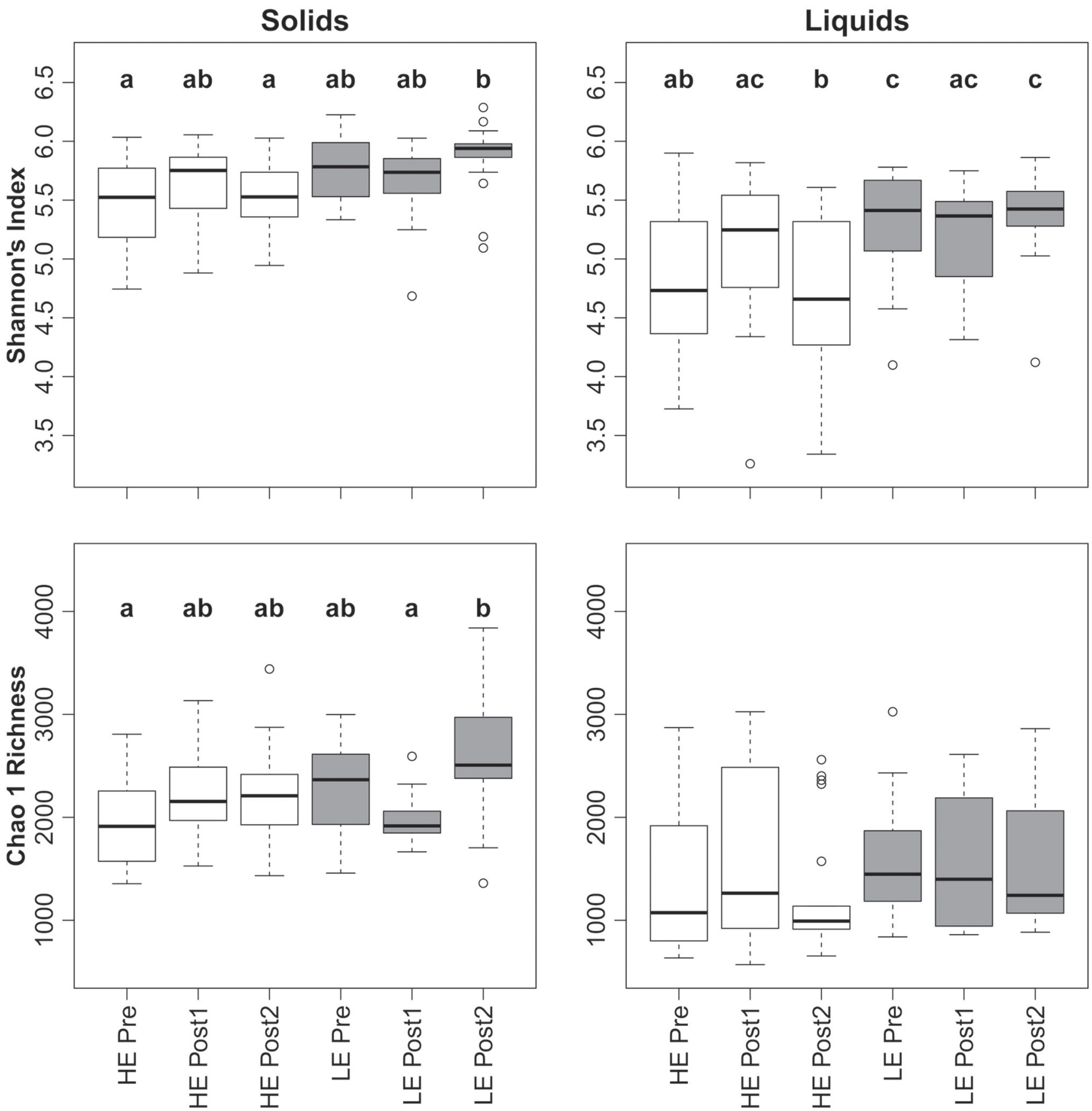

Figure 4. Alpha diversity statistics expressing evenness (Shannon's index) and richness (Chao 1 richness) of bacterial communities in solid and liquid ruminal contents of 3 higher milk production efficiency (HE) and 3 lower milk production efficiency (LE) cows in the study, pooled by sampling period. Data are expressed as medians with boxes showing the 25 and $75 \%$ quartiles and lines for 1.5 times the interquartile range. Outliers are shown as dots. Groups with different letters within a plot are different (false discovery rate, $P<0.05$ ). Sampling periods: Pre $=-8$ to $0 \mathrm{~d}$ relative to date of exchange; Post $1=0$ to $7 \mathrm{~d}$ after exchange; Post $2=10$ to $56 \mathrm{~d}$ after exchange. 
3; https://doi.org/10.3168/jds.2017-12746), and HE and LE samples $(P<0.001)$. The effect of sampling period on the Bray-Curtis metric was different for HE and LE cows $(P<0.001)$.

4255 and 4261 , solids
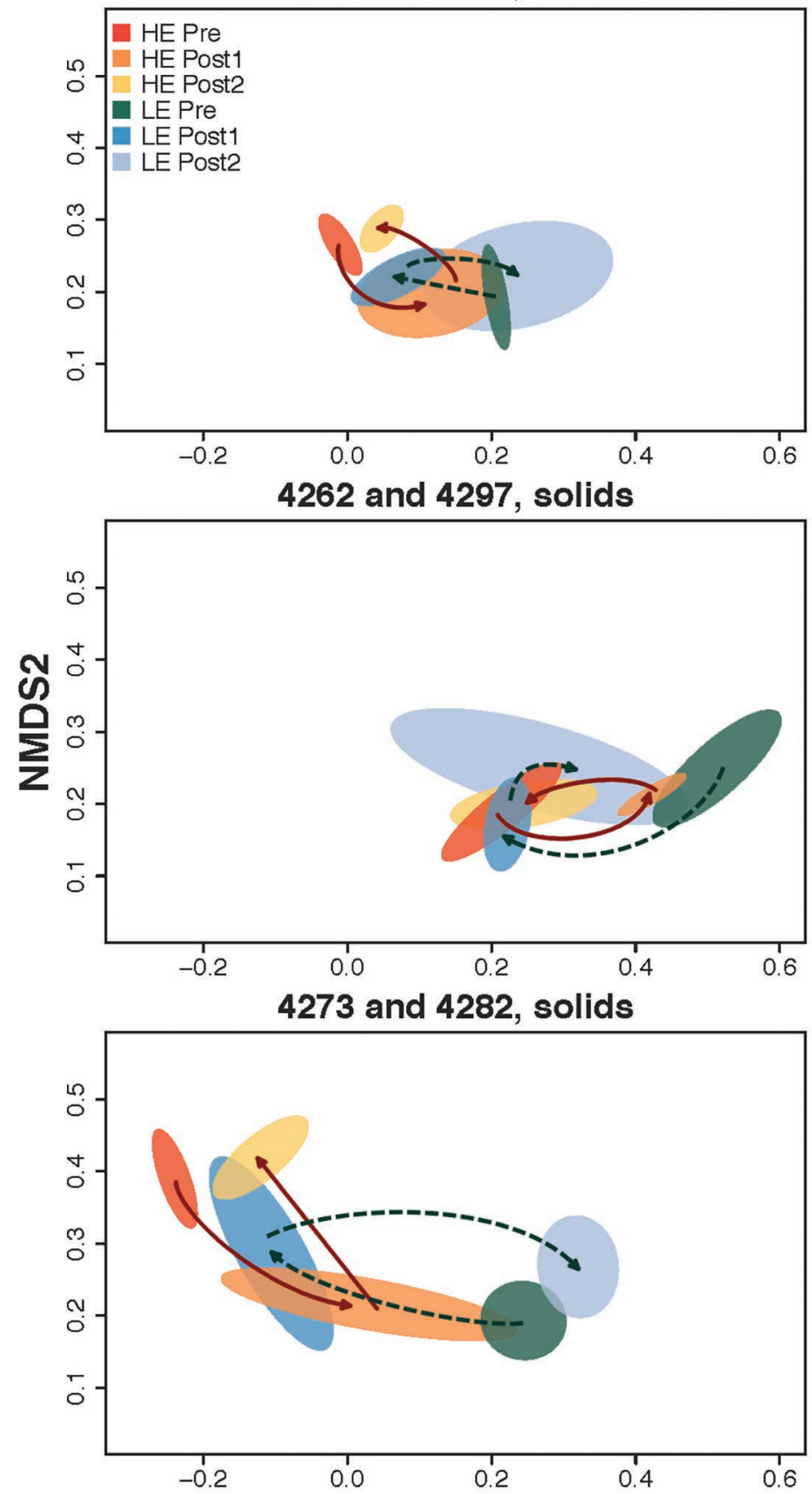

Qualitatively, the general trend in the solid samples shows that a donor-like community in Post1, induced by the exchange and different from Pre, returned to a community similar to Pre in the host in Post2. Cow
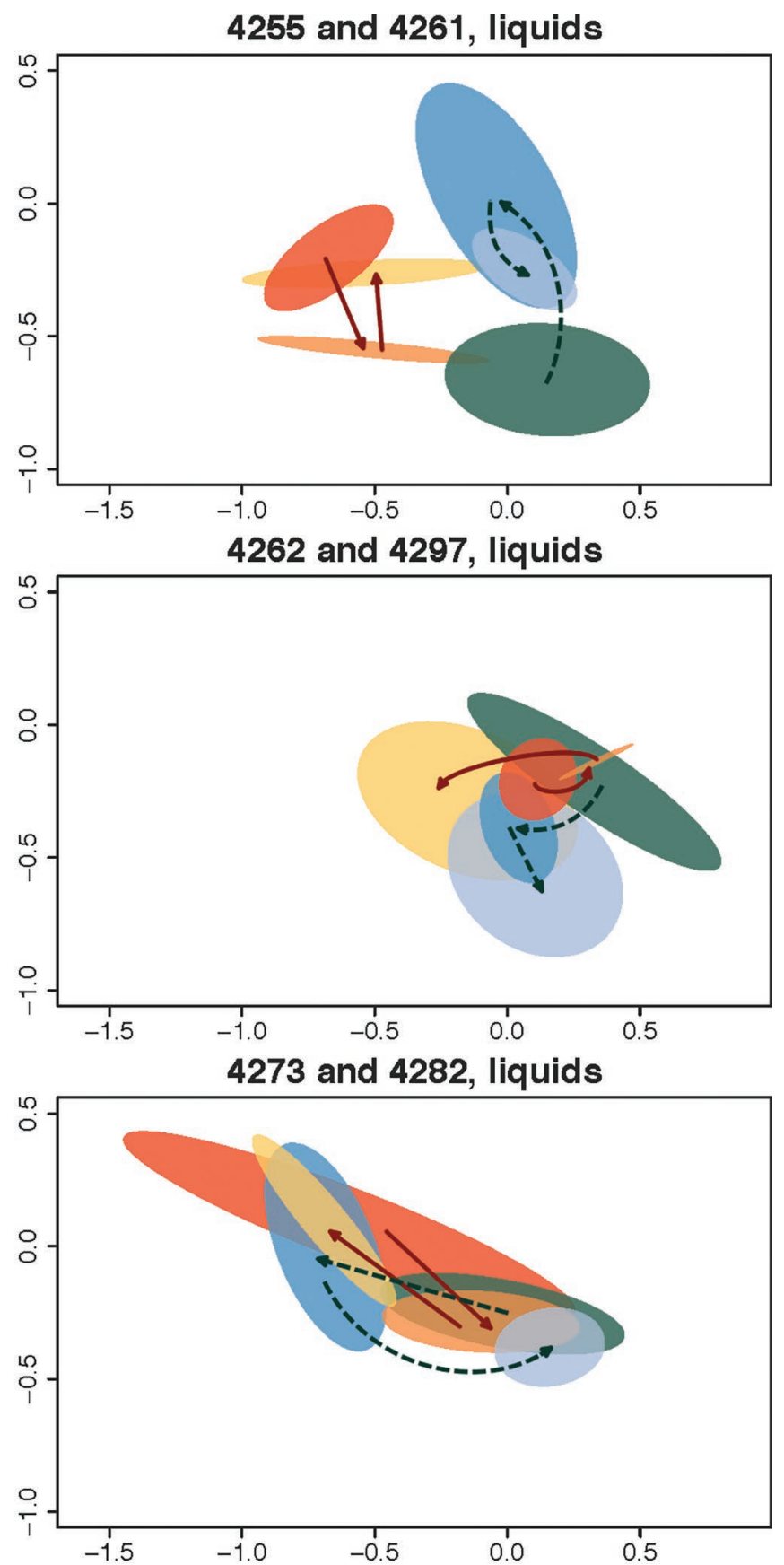

NMDS1

Figure 5. Ellipses representing 95\% confidence intervals of nonmetric multidimensional scaling (NMDS) coordinates of the Bray-Curtis diversity metric for ruminal liquids and solids in 3 pairs of animals before and following near-total ruminal contents exchange. Ellipses are colored by animal efficiency, with cool colors indicating lower efficiency (LE) cows within each pair and warm colors indicating higher efficiency (HE) cows within each pair. The darkest colors (red and green) indicate the pre-exchange period, medium colors represent the Post1 period ( $0-7$ $\mathrm{d}$ after the exchange), and the lightest colors represent the Post2 period (10-56 d after the exchange). Arrows between ellipses indicate time progression for the community within cow. 
4297 (LE) is the only animal for which the Post2 ellipse is not closer to the host Pre ellipse than the donor Pre ellipse, presumably because of the large variation in $\mathrm{BCC}$ of this animal for this time period. The BCC of ruminal solids was distinct between HE and LE members of each pair in Pre (pairwise permutational multivariate ANOVA, FDR-adjusted $P \leq 0.05$, Supplemental Table S2; https://doi.org/10.3168/jds.2017-12746). In cows 4255 (HE), 4261 (LE), 4262 (HE), and 4282 (LE), Post1 was similar to the donor Pre (FDR-adjusted $P$ $>0.05$ ) and dissimilar from the host Pre state (FDRadjusted $P \leq 0.05$ ), suggesting that the original host community had not re-established itself during this first week following contents exchange. In cows 4273 (HE) and 4297 (LE), Post1 was distinct from Pre of both host and donor (FDR-adjusted $P \leq 0.05$ ), suggesting a dynamic community not yet dominated by either the original donor or recipient communities. For cows 4255 (HE) and 4261 (LE), Post2 was similar to host Pre (FDR-adjusted $P>0.05$ ) and dissimilar from Post1 (FDR-adjusted $P \leq 0.05$ ), suggesting that the original community of the host had largely re-established itself. For all other animals, Post2 was distinct from both host Pre and Post1 (FDR-adjusted $P>0.05$ ), suggesting that full re-establishment of the original community had not yet occurred, although it had moved in that direction (Figure 5).

Qualitative analysis of the Bray-Curtis dissimilarity of liquid samples reflects a similar pattern to that of the solids, but greater variation within MPE groups obscured some differences between groups. In most cases, BCC during Post1 can be seen to differ from that of host Pre and similar to that of donor Pre, after which a return to the original host state or an intermediate position occurred in Post2. Cow 4297 (LE) is the only animal for which Post2 was more different from host Pre than was Post1. The liquid-associated BCC was distinct between all LE and HE partners before the exchange (pairwise permutational multivariate ANOVA, FDR-adjusted $P \leq 0.05$, Supplemental Table S2; https://doi.org/10.3168/jds.2017-12746). The liquidassociated community did not change significantly over the course of the study in cow 4255 (FDR-adjusted $P$ $>0.05$ ). In cows 4261 (LE), 4262 (HE), 4282 (HE), and 4273 (HE), Post1 was similar to donor Pre (FDRadjusted $P>0.05)$ and dissimilar from the host Pre (FDR-adjusted $P \leq 0.05$ ), suggesting that the original host community had not re-established itself during this first week following contents exchange. The Post1 in cow 4297 (LE) was dissimilar from both host and donor Pre (FDR-adjusted $P \leq 0.05$ ), suggesting a dynamic community not yet dominated by either the original donor or recipient communities. The Post2 in cows 4261 (LE) and 4273 (HE) was dissimilar from the host Pre (FDR-adjusted $P \leq 0.05$ ), suggesting that full re-establishment of the original community had not yet occurred. In cow 4261, Post2 remained similar to Post1 (FDR-adjusted $P>0.05$ ), but in cow 4273 Post2 was dissimilar from Post1 (FDR-adjusted $P \leq 0.05$ ). Both cows 4262 (HE) and 4297 (LE) returned to native state with similarity to host Pre (FDR-adjusted $P>0.05$ ), but cow 4297 was also similar to Post1 (FDR-adjusted $P>0.05)$.

The same patterns were seen in BCC as assessed by the Jaccard metric (Supplemental Data Sheet 3 and Supplemental Table S3; https://doi.org/10.3168/ jds.2017-12746). Thus, by both methods, BCC differed not only between liquid and solid phases and between HE and LE groups, but also differed across sampling periods in most cows.

\section{DISCUSSION}

Milk production efficiency as a particular measure of feed efficiency is an important metric of dairy performance that can affect both the profitability and environmental footprint of dairy operations. It is widely accepted that the microbial community of the rumen has the potential to affect $\mathrm{FE}$ in beef production systems (Carberry et al., 2012; Hernandez-Sanabria et al., 2010, 2012; Myer et al., 2015a), but only a few studies have examined the relationship between microbial community composition and FE in dairy cattle. Jami et al. (2014) reported differences in BCC among cows that displayed differences in $\mathrm{FE}$, determined from single ruminal samples collected from 15 individual cows at an undefined stage of lactation. Jewell et al. (2015) demonstrated within-pair differences in BCC in both ruminal solids and liquids in cows that differed in DMI at equivalent levels of ECM production within 3 discrete ranges of DIM (68-72, 151-157, and 251-257 d) over 2 lactations. More recently, Shabat et al. (2016) demonstrated differences in bacterial and archaeal community composition between 40 higher efficiency and 38 lower efficiency cows within mid-lactation (50-150 DIM). However, in terms of microbial community composition, all of these studies were limited to determining correlations between $\mathrm{FE}$ and the relative abundance of specific taxa. Moreover, specific OTU whose abundance is related to feed efficiency across multiple studies have not been identified.

In the present study, we used 3 of the pairs of cows identified in the Jewell et al. (2015) report as divergent in ECM/DMI, as subjects for a near-total exchange of ruminal contents, to determine responses in both MPE and BCC over time. Based upon the observed 
association between BCC and MPE (Jewell et al., 2015) and upon a previous demonstration that neartotal exchange of ruminal contents resulted in a gradual return of the bacterial community over several weeks to resemble its original BCC (Weimer et al., 2010a), we hypothesized that near-total exchange of ruminal contents between higher and lower-MPE cows would result in at least a transient change in MPE before the bacterial community reassorted itself to resemble its original species composition. Here, the significant differences between posttransfer and pretransfer MPE support that hypothesis for the LE cows, and supported the hypothesis with the HE cows when one outlier animal was removed from the analysis. That the outlier could be detected within her efficiency status group $(\mathrm{n}=3)$ reinforces the point that she was sufficiently different in response from the other 2 animals to be detected as different. Challenges are certainly created by the necessity of using a small number of animals for the number of measurements made, and how individual animal variation can affect our ability to detect differences. However, that significance levels of $P=0.07$ or $P<0.01$ were achieved with $\mathrm{n}=3$ in each group indicates that, even with few experimental units, the differences in response were authentic.

Numeric trends from the residual analyses reflecting expected changes in MPE were observed in 5 of 6 cows, but their interpretation was complicated by the small number of animals and the well-known difficulty of obtaining statistically significant data for MPE over short time periods. For example, Connor et al. (2012) were able to demonstrate differences in feed efficiency in Holstein cows over a 56-d period that reflected differences over the full lactation cycle. Such long analysis periods are incompatible with short-term changes over which a ruminal microbial community might reassemble to more closely resemble its original community composition following even extreme perturbation. To partially circumvent the problems of accurate measurements of daily MPE and the natural changes in MPE over time in the lactation cycle, we performed regression analysis to detect deviations from expected MPE over shorter time periods, and in 5 of the 6 cows these deviations were numerically consistent with hypothesized transient shifts in MPE. Analysis of the residuals (observed MPE minus predicted MPE) across all samples within the 2 efficiency groups revealed a transient increase in MPE for the LE cows upon exchange with a HE donor inoculum. The converse exchange for the HE cows with ruminal contents from the LE cows exhibited numeric, but not statistically significant effects, due perhaps to the unexpected and atypical MPE behavior of 1 of the 3 cows (i.e., increased MPE during the entire period of the experiment even though that cow was very late in lactation). Additional experiments are warranted to test the hypothesis that near-total replacement of ruminal contents of $\mathrm{HE}$ cows with those of LE cows transiently reduces MPE.

Analysis of BCC using next-generation sequencing of $16 \mathrm{~S}$ rRNA genes in both solid and liquid ruminal samples revealed that in general BCC differed between each cow within a pair, regardless of how different they were from one another in MPE (e.g., cow 4273, an outlier in terms of the time course of its MPE, displayed no greater dissimilarity from its pair mate, cow 4282 , than did the other cows differ from their pair mates, at least when visualized via NMDS plot). This observation, along with the known host specificity of the ruminal microbial community, suggests that although cattle appear to have a ruminal "core microbiome" with respect to the most abundant phyla and genera (Jami and Mizrahi, 2012; Petri et al., 2013), there is sufficient variation in the identity and relative abundance of microbial species across individuals to conclude that there is no typical or atypical microbial community.

The BCC also strongly resembled that of the donor cow immediately after the contents exchange, but within $10 \mathrm{~d}$ came to more resemble that of the host before the contents exchange. This time frame approximated that over which MPE returned to values predicted by regression analysis of MPE with time, suggesting that BCC and MPE are linked. This time course is also consistent with recent work in which dramatic shifts in diet in cattle (e.g., corn silage vs. sugarcane) resulted in a re-stabilization of the ruminal bacterial community (albeit with a different composition) within 6 to $13 \mathrm{~d}$ (Machado et al., 2016). Although we observed resilience for both the solid- and liquid-phase communities, the solid-phase community displayed greater elasticity [i.e., more rapid return to the preexchange condition (Westman, 1978), generally by $10 \mathrm{~d}$ after contents exchange]. This observation was surprising and somewhat counterintuitive because the turnover of solids in the rumen is slower than that of liquids; the solids contain the vast majority ( $80 \%$ or more) of the ruminal bacterial community (Yang et al., 1989, 2001), and the bacteria associated with ruminal solids (particularly the fiber degraders) would be expected to grow more slowly than would planktonic (liquid-phase) bacteria that subsist primarily on soluble substrates. The liquid phase community also displayed resilience, but it was more variable in its time course, and in several cows it did not return to its original composition by the end of the 56-d postexchange period. Resilience on the whole is likely dictated primarily by the more abundant solids-phase community, with only modest dilution of overall community resilience by the liquid-phase community. The more rapid restoration of the solids-phase community 
suggests that individual animals exert great control over factors that determine differences in this community, such as meal patterning (frequency and amount of eating), solids passage rate, extent or efficiency of rumination in processing feeds (or both), and ruminal $\mathrm{pH}$ dynamics [which is thought to have stronger effects on the particle-associated fiber-degrading community (Russell and Wilson, 1996)].

The apparent role of the ruminal microbiome in contributing to differences in MPE raises the question of the mechanism by which such control might be exerted. The most obvious candidates are the end products of ruminal fermentation (VFA, the major source for energy and metabolic precursors for the ruminant), and microbial cells and their components (particularly cell protein, an important source of AA for the host). Shabat et al. (2016) reported that HE cows displayed greater conversion of feed to VFA, higher ruminal concentrations of total VFA, and a higher proportion of propionate, butyrate, valerate, and isovalerate than did LE cows. Despite the much smaller number of cows on our study, we also observed parallel and highly significant differences in VFA amounts and proportions between the HE and LE cows. The HE cows had higher total VFA concentrations; higher molar percentages of valerate and its precursor, propionate; and lower molar percentages of butyrate and its precursor, acetate. The data are consistent with Shabat's model of increased feed efficiency expected from enhanced delivery of the gluconeogenic substrate, propionate, to the host. However, interpretation of the effect of VFA patterns on efficiency is complicated by the known poor relationship between measured VFA concentrations in the rumen and the actual delivery of VFA to the host (Hall et al., 2015). Moreover, in cases where we observed numerical differences in total VFA concentration or VFA proportions between cows within a pair, exchange of ruminal contents resulted in rapid (within $\sim 1 \mathrm{~d}$ ) return of these variables to their preexchange conditions - much more rapid than the return of MPE to their values predicted by regression analysis. This rapid reestablishment of VFA profiles, also reported in another study that employed contents exchange (Weimer et al., 2010a), suggests that, whereas VFA are essential as energy sources for the host and may ultimately contribute to differences in MPE between animals, measurable concentrations and proportions of VFA in the rumen are largely controlled by the host (perhaps including host interactions with other functionalities of the ruminal microbiota) and by themselves do not fully explain differences in feed efficiency among host animals.

Shabat et al. (2016) specifically proposed 2 bacterial species, Megasphaera elsdenii and Coprococcus catus, as important determinants of feed efficiency in dairy cows. In their study both species were significantly more abundant in the rumens of HE than LE cows, and both are known to convert lactate to propionate (a VFA whose abundance was elevated in the HE cows). However, even on the high-concentrate diet used $(70 \%$ concentrates, DM basis), their reported mean relative abundances of $M$. elsdenii $[0.075 \pm 0.015 \%$ (mean \pm $\mathrm{SEM})$ in HE cows, $0.032 \pm 0.015 \%$ in LE cows] and $C$. catus $(0.00043 \pm 0.00038 \%$ in $\mathrm{HE}$ cows, not detected in LE cows) were very low, compared with the relative abundance of well-known producers of propionate (or its precursors, succinate or lactate) such as genus Prevotella (present at 33-38\% of the bacterial community), suggesting that the overall effect on propionate production by these 2 species may be minimal. In our study, the relative abundance of both species was also extremely low ( $M$. elsdenii: $0.0252 \pm 0.0015 \%$ in $\mathrm{HE}$ cows, $0.0028 \pm 0.013 \%$ in LE cows; C. catus: 0.0099 $\pm 0.014 \%$ in HE cows, $0.059 \pm 0.018 \%$ in LE cows; Wilcoxon rank-sum, $P=0.021$ and 0.301 , respectively). Moreover, M. elsdenii has been noted in numerous studies (Latham et al., 1972; Palmonari et al., 2010; Weimer et al., 2010b; Mohammed et al., 2012; Rico et al., 2015) to be highly abundant in dairy cows experiencing milk fat depression, a condition under which ECM (and thus feed efficiency) is depressed due to the outsized influence of milk fat content on milk energy. In view of these contrasting results, the potential involvement of $M$. elsdenii and C. catus as agents of both quantitatively significant propionate production and higher feed efficiency remains enigmatic and merits further investigation.

Although improved energy availability to the host is a logical mechanism by which MPE might be improved, other factors may contribute as well. For example, some evidence indicates that inocula from $\mathrm{HE}$ cows display higher yields of microbial protein than do those of LE cows fermenting the same TMR in vitro (Contreras-Govea et al., 2016). In addition, pure cultures of bacteria from the 2 most abundant phyla in the rumen, Bacteroidetes and Firmicutes, vary widely in cell yield, with species now classified within the Prevotella (phylum Bacteroidetes) generally producing substantially higher yields than representatives of the Firmicutes when grown in chemostats at similar rates on similar substrates (Russell and Baldwin, 1979a,b; Russell and Dombrowski, 1980). These data suggest that enhanced availability of high-quality microbial protein of optimum AA composition may contribute to improved MPE. Alternatively, or in conjunction with changes in the profile of ruminal fermentation products and protein supply, potential immunomodulatory (Maslowski and Mackay, 2011) or endocrine effects (Dinan and Cryan, 2012) related to gut microbiota may 
play an as-yet-undescribed role in determining animal performance. Finally, we did not examine changes in the archaeal, protozoal, or fungal components of the ruminal microbiome resulting from contents exchange, and the known contributions of these groups to ruminal metabolism would be expected to have some effect on MPE (Ushida et al., 1991; Zhou et al., 2009; Shabat et al., 2016).

Although the mechanisms underlying improved MPE have yet to be fully characterized, the results presented here suggest that attempts to improve MPE through modification of the ruminal microbiota are worthy of further exploration, but must recognize the inherent inertia of the host community, and its resilience upon even very dramatic perturbation (Weimer, 2015). That said, the specific case of unexpected improvement in MPE in 1 cow (cow 4273) upon transplantation of ruminal contents from a less efficient cow, along with the shift in its community composition to one intermediate between donor and recipient, suggests that even communities that are apparently well-adapted to their host may not be immutable, and may not have always been fully optimized for MPE (in this case, even by her third lactation). However, our work does suggest that whole microbial community transplants have the ability, in some cows, to intrinsically alter complex host phenotype, a property that has been demonstrated for traits such as obesity in mouse models (Ridaura et al., 2013). To better understand how manipulation of the ruminal microbiome affects host phenotypes like MPE, we suggest that future research should include, in addition to the use of larger numbers of animals, an examination of the effects on MPE of dosing with whole communities or specific community members at various stages of the animal's life (Yáñez-Ruiz et al., 2015), which may enhance the likelihood of favorably altering both ruminal community composition and MPE. Finally, the studies here focused exclusively on the interrelationship between MPE and the ruminal microbiota. Research on the hindgut (including total-tract digestibility measurements coupled with analysis of hindgut microbial communities) may further inform the microbial contribution to interanimal differences in feed efficiency (Myer et al., 2015b), although it is likely impractical to perform contents exchange studies with the hindgut.

\section{ACKNOWLEDGMENTS}

We thank C. L. Odt (USDFRC) for technical assistance; M. Maroney (UW) for rumen cannulation surgeries; R. Skoyen, M. W. Hintz, K. Pickar, and the Prairie du Sac barn crew (UW) for feeding and milking the cows; K. Dill-McFarland (UW), U. Hymes-Fecht,
J. Pitas, and G. I. Zanton for assistance in the ruminal contents exchanges; and K. F. Kalscheur and G. I. Zanton (USDFRC) for useful discussions. This research was supported by USDA NIFA AFRI (Washington, DC) Foundational grant 2015-67015-23246 and USDAAgricultural Research Service (Washington, DC) CRIS project 5090-21000-024-00-D. Mention of specific products is for informational purposes only, and does not constitute an endorsement or warranty by USDA over other products that may also be suitable.

\section{REFERENCES}

Arndt, C., J. M. Powell, M. J. Aguerre, P. M. Crump, and M. A. Wattiaux. 2015. Feed conversion efficiency in dairy cows: Repeatability, variation in digestion and metabolism of energy and nitrogen, and ruminal methanogens. J. Dairy Sci. 98:3938-3950.

AOAC. 1990. Official Methods of Analysis. 15th ed. Association of Official Analytical Chemists, Arlington, VA.

Bray, R. J., and J. T. Curtis. 1957. An ordination of the upland forest communities of Southern Wisconsin. Ecol. Monogr. 27:325-349.

Capper, J. L., R. A. Cady, and D. E. Baumann. 2009. The environmental impact of dairy production: 1944 compared with 2007. J. Anim. Sci. 87:2160-2167. https://doi.org/10.2527/jas.2009-1781.

Carberry, C. A., D. A. Kenny, S. Han, M. S. McCabe, and S. M. Waters. 2012. Effect of phenotypic residual feed intake and dietary forage content on the rumen microbial community of beef cattle. Appl. Environ. Microbiol. 78:4949-4958. https://doi.org/10.1128/ AEM.07759-11.

Chao, A. 1984. Nonparametric estimation of the number of classes in a population. Scand. J. Stat. 11:265-270.

Connor, E. E. 2015. Invited review: Improving feed efficiency in dairy production: Challenges and possibilities. Animal 9:395-408. https://doi.org/10.1017/S1751731114002997.

Connor, E. E., J. L. Hutchison, K. M. Olson, and H. D. Norman. 2012 Triennial Lactation Symposium: Opportunities for improving milk production efficiency in dairy cattle. J. Anim. Sci. 90:1687-1694. https://doi.org/10.2527/jas.2011-4528.

Contreras-Govea, F. E., R. E. Muck, P. J. Weimer, and U. HymesFecht. 2016. In vitro fermentation of treated alfalfa silage using ruminal inocula from high and low feed-efficient lactating cows. J. Appl. Microbiol. 121:333-340. https://doi.org/10.1111/jam.13103.

DeSantis, T. Z., P. Hugenholtz, N. Larsen, M. Rojas, E. L. Brodie, K. Keller, T. Huber, D. Dalevi, P. Hu, and G. L. Andersen. 2006. Greengenes, a chimera-checked 16S rRNA gene database and workbench compatible with ARB. Appl. Environ. Microbiol. 72:5069-5072

Dinan, T. G., and J. F. Cryan. 2012. Regulation of the stress response by the gut microbiota: Implications for psychoneuroendocrinology. Psychoneuroendocrinology 37:1369-1378. https://doi. org/10.1016/j.psyneuen.2012.03.007.

Dobson, H., R. F. Smith, M. D. Royal, C. H. Knight, and I. M. Sheldon. 2007. The high-producing dairy cow and its reproductive performance. Reprod. Domest. Anim. 42(Suppl. 2):17-23. https:// doi.org/10.1111/j.1439-0531.2007.00906.x.

Edgar, R. C., B. J. Haas, J. C. Clemente, C. Quince, and R. Knight. 2011. UCHIME improves sensitivity and speed of chimera detection. Bioinformatics 27:2194-2200.

Good, I. J. 1953. The population frequencies of species and the estimation of population parameters. Biometrika 40:237-264.

Hall, M., T. D. Nennich, P. H. Doane, and G. E. Brink. 2015. Total volatile fatty acid concentrations are unreliable estimators of treatment effects on ruminal fermentation in vivo. J. Dairy Sci. 98:3988-3999. https://doi.org/10.3168/jds.2014-8854.

Henderson, G., F. Cox, S. Kittelmann, V. H. Miri, M. Zethof, S. J. Noel, G. C. Waghorn, and P. H. Janssen. 2013. Effect of DNA ex- 
traction methods and sampling techniques on the apparent structure of cow and sheep rumen microbial communities. PLoS One 8:e74787. https://doi.org/10.1371/journal.pone.0074787.

Hernandez-Sanabria, E., L. A. Goonewardene, Z. Wang, N. Durunna, S. S. Moore, and L. L. Guan. 2012. Impact of feed efficiency and diet on adaptive variations in the bacterial community in the rumen fluid of cattle. Appl. Environ. Microbiol. 78:1203-1214. https://doi.org/10.1128/AEM.05114-11.

Hernandez-Sanabria, E., L. L. Guan, L. A. Goonewardene, M. Li, D. F. Mujibi, P. S. Stothard, S. S. Moore, and M. C. Leon-Quintero. 2010. Correlation of particular bacterial PCR-denaturing gradient gel electrophoresis patterns with bovine ruminal fermentation parameters and feed efficiency traits. Appl. Environ. Microbiol. 76:6338-6350. https://doi.org/10.1128/AEM.01052-10.

Jaccard, P. 1912. The distribution of the flora in the alpine zone. New Phytol. 11:37-50.

Jami, E., and I. Mizrahi. 2012. Similarity of the ruminal bacteria across individual lactating cows. Anaerobe 18:338-343.

Jami, E., B. A. White, and I. Mizrahi. 2014. Potential role of the bovine rumen microbiome in modulating milk composition and feed efficiency. PLoS One 9:e85423. https://doi.org/10.1371/journal. pone. 0085423 .

Jewell, K. A., C. McCormick, C. L. Odt, P. J. Weimer, and G. Suen. 2015. Ruminal bacterial community composition in dairy cows is dynamic over the course of multiple lactations and correlates with feed efficiency. Appl. Environ. Microbiol. 81:4697-4710. https:// doi.org/10.1128/AEM.00720-15.

Kozich, J. J., S. L. Westcott, N. T. Baxter, S. K. Highlander, and P. D. Schloss. 2013. Development of a dual-index sequencing strategy and curation pipeline for analyzing amplicon sequence data on the MiSeq Illumina sequencing platform. Appl. Environ. Microbiol. 79:5112-5120. https://doi.org/10.1128/AEM.01043-13.

Latham, M. J., J. E. Storrey, and M. E. Sharpe. 1972. Effect of lowroughage diets on the microflora and lipid metabolism in the rumen. Appl. Microbiol. 24:871-877.

Linn, J., M. Raeth-Knight, S. Fredin, and A. Bach. 2007. Feed efficiency in lactating dairy cows. Page 10 in Proc. Colorado Dairy Nutrition Conf., Colorado Springs, CO. http://www.cvmbs. colostate.edu/ilm/proinfo/cdn/2007/Feed Efficiency in Lactating Dairy Cows.pdf.

Machado, M. G., E. Dettman, H. C. Mantovani, S. C. Valardes Filho, C. B. P. Bento, M. I. Marcondes, and A. S. Assuncao. 2016. Evaluation of length of adaptation period for changeover and crossover experiments with cattle fed tropical forages. Anim. Feed Sci. Technol. 222:132-148.

Maslowski, K. M., and C. R. Mackay. 2011. Diet, gut microbiota and immune responses. Nat. Immunol. 12:5-9.

Mohammed, R., D. M. Stevenson, K. A. Beauchemin, R. E. Muck, and P. J. Weimer. 2012. Changes in ruminal bacterial community composition following feeding of alfalfa silage inoculated with a commercial silage inoculant. J. Dairy Sci. 95:328-339.

Myer, P. R., T. P. Smith, J. E. Wells, L. A. Kuehn, and H. C. Freetly. 2015a. Rumen microbiome from steers differing in feed efficiency. PLoS One 10:e0129174.

Myer, P. R., J. E. Wells, T. P. Smith, L. A. Kuehn, and H. C. Freetly. 2015b. Microbial community profiles of the colon from steers differing in feed efficiency. Springerplus 4:454.

NRC. 2001. Nutrient Requirements of Dairy Cattle, 7th rev. ed. Natl. Acad. Press, Washington, DC

Okansen, J. A., F. G. Blanchet, R. Kindt, P. Legendre, P. R. Minchin, R. B. O'Hara, G. L. Simpson, P. Solymos, M. H. H. Stevens, and H. Wagner. 2016. vegan: Community Ecology Package. http:// CRAN.R-project.org/package=vegan.

Palmonari, A., D. M. Stevenson, D. R. Mertens, C. W. Cruywagen, and P. J. Weimer. 2010. pH dynamics and bacterial community composition in the rumen of lactating dairy cows. J. Dairy Sci. 93:279-287.

Petri, R. M., T. Schwaiger, G. B. Penner, K. A. Beauchemin, R. J. Forster, J. J. McKinnon, and T. A. McAllister. 2013. Characterization of the core rumen microbiome in cattle during transition from forage to concentrate as well as during and after an acidotic challenge. PLoS One 8:e83424.

Pruesse, E., C. Quast, K. Knittel, B. M. Fuchs, W. Ludwig, J. Peplies, and F. O. Glöckner. 2007. SILVA: A comprehensive online resource for quality checked and aligned ribosomal RNA sequence data compatible with ARB. Nucleic Acids Res. 35:7188-7196.

Pryce, J., J. Arias, P. Bowman, S. Davis, K. Macdonald, G. Waghorn, W. J. Wales, Y. J. Williams, R. J. Spelman, and B. J. Hayes.2012. Accuracy of genomic predictions of residual feed intake and 250day body weight in growing heifers using 625,000 single nucleotide polymorphism markers. J. Dairy Sci. 95:2108-2119.

R Development Core Team. 2011. A Language and Environment for Statistical Computing. The R Foundation for Statistical Computing. http://www.R-project.org

Rico, D. E., S. H. Preston, J. M. Risser, and K. J. Harvatine. 2015. Rapid changes in key ruminal microbial populations during the induction of and recovery from diet-induced milk fat depression in dairy cows. Br. J. Nutr. 114:358-367.

Ridaura, V. K., J. J. Faith, F. E. Rey, J. Cheng, A. E. Duncan, A. L. Kau, N. W. Griffin, V. Lombard, B. Henrissat, J. R. Bain, M. J. Muehlbauer, O. Ilkayeva, C. F. Semenkovich, K. Funai, D. K. Hayashi, B. J. Lyle, M. C. Martini, L. K. Ursell, J. C. Clemente, W. Van Treuren, W. A. Walters, R. Knight, C. B. Newgard, A. C. Heath, and J. I. Gordon. 2013. Gut microbiota from twins discordant for obesity modulate metabolism in mice. Science 341:1241214. https://doi.org/10.1126/science.1241214.

Rorabacher, D. B. 1991. Statistical treatment for rejection of deviant values: critical values of Dixon's "Q" parameter and related subrange rations at the 95\% confidence level. Anal. Chem. 63:139-146.

Russell, J. B., and R. L. Baldwin. 1979a. Comparison of substrate affinities among several rumen bacteria: A possible determinant of rumen bacterial competition. Appl. Environ. Microbiol. 37:531536

Russell, J. B., and R. L. Baldwin. 1979b. Comparison of maintenance energy expenditures and growth yields among several rumen bacteria grown on continuous culture. Appl. Environ. Microbiol. $37: 537-543$.

Russell, J. B., and D. B. Dombrowski. 1980. Effect of pH on the efficiency of growth by pure cultures of rumen bacteria in continuous culture. Appl. Environ. Microbiol. 39:604-610.

Russell, J. B., and D. B. Wilson. 1996. Why are ruminal cellulolytic bacteria unable to digest cellulose at low pH? J. Dairy Sci 79:1503-1509.

Schloss, P. D., S. L. Westcott, T. Ryabin, J. R. Hall, M. Hartmann, E. B. Hollister, R. A. Lesniewski, B. B. Oakley, D. H. Parks, C. J. Robinson, J. W. Sahl, B. Stres, G. G. Thallinger, D. J. Van Horn, and C. F. Weber. 2009. Introducing mothur: Open-source, platform-independent, community-supported software for describing and comparing microbial communities. Appl. Environ. Microbiol. 75:7537-7541.

Shabat, S. K. B., G. Sasson, A. Doron-Faigenboim, T. Durman, S. Yaacoby, M. E. Berg Miller, B. A. White, N. Shterzer, and I. Mizrahi. 2016. Specific microbiome-dependent mechanisms underlie the energy harvest efficiency of ruminants. ISME J. https://doi. org/10.1038/ismej.2016.62.

Shannon, C. E. 2001. A mathematical theory of communication. Mob. Comput. Commun. Rev. 5:3-55.

Stevenson, D. M., and P. J. Weimer. 2007. Dominance of Prevotella and low abundance of classical ruminal bacterial species in the bovine rumen revealed by relative quantification real-time PCR. Appl. Microbiol. Biotechnol. 75:165-174.

Tyrrell, H. F., and J. T. Reid. 1965. Prediction of the energy value of cow's milk. J. Dairy Sci. 48:1215-1223.

Ushida, K., J. Jouany, and D. Demeyer. 1991. Effects of the presence or absence of rumen protozoa on the efficiency of utilisation of concentrate and fibrous feeds. Pages 225-254 in Physiological Aspects of Digestion and Metabolism in Ruminants, Proc. 7th Int. Symp. on Ruminant Physiol. T. Tsuda, Y. Sasaki, and R. Kawashima, ed. Acad. Press, New York, NY.

VandeHaar, M. J., L. E. Armentano, K. Weigel, D. M. Spurlock, R. J. Tempelman, and R. Veerkamp. 2016. Harnessing the genetics of 
the modern dairy cow to continue improvements in feed efficiency. J. Dairy Sci. 99:4941-4954. https://doi.org/10.3168/jds.201510352.

Weimer, P. J. 2015. Redundancy, resiliency and individuality of the ruminal microbiome and their implications for engineering improved ruminal fermentations. Front. Microbiol. 6:296.

Weimer, P. J., Y. Shi, and C. L. Odt. 1991. A segmented gas/liquid delivery system for continuous culture of microorganisms on solid substrates, and its use for growth of Ruminococcus flavefaciens on cellulose. Appl. Microbiol. Biotechnol. 36:178-183.

Weimer, P. J., D. M. Stevenson, H. C. Mantovani, and S. L. C. Man 2010a. Host specificity of the ruminal bacterial community of the dairy cow following near-total exchange of ruminal contents. J. Dairy Sci. 93:5902-5912.

Weimer, P. J., D. M. Stevenson, and D. R. Mertens. 2010b. Shifts in bacterial community composition in the rumen of lactating dairy cows under conditions of milk fat depression. J. Dairy Sci. 93:265-278.
Westman, W. E. 1978. Measuring the inertia and resilience of ecosystems. Bioscience 28:705-710. https://doi.org/10.2307/1307321.

Yáñez-Ruiz, D. R., L. Abecia, and C. J. Newbold. 2015. Manipulating rumen microbiome and fermentation through interventions early in life: A review. Front. Microbiol. 6:1133. https://doi.org/10.3389/ fmicb.2015.01133.

Yang, W. Z., K. A. Beauchemin, and L. M. Rode. 2001. Effect of dietary factors on distribution and chemical composition of liquid- or solid-associated bacterial populations in the rumen of dairy cows. J. Anim. Sci. 79:2736-2746.

Yang, W. Z. C. Poncet, and A. Escobar. 1989. Influence of the level of concentrate in sheep diet on composition and distribution of bacteria in ruminal and duodenal contents and duodenal bacterial flow estimation. Austr. J. Anim. Sci. 2:394-395.

Zhou, M., E. Hernandez-Sanabria, and L. L. Guan. 2009. Assessment of the microbial ecology of ruminal methanogens in cattle with different feed efficiencies. Appl. Environ. Microbiol. 75:6524-6533. 